\title{
Hydrological gravity response detection using a gPhone below- and aboveground
}

\author{
Toshiyuki Tanaka ${ }^{1}$, Rikio Miyajima ${ }^{1}$, Hideaki Asai ${ }^{2 *}$, Yasuharu Horiuchi², \\ Koji Kumada $^{2}$, Yasuhiro Asai ${ }^{1}$, and Hiroshi Ishii ${ }^{1}$ \\ ${ }^{1}$ Tono Research Institute of Earthquake Science, Association for the Development of Earthquake Prediction, \\ 1-63 Yamanouchi, Akeyo-cho, Mizunami 509-6132, Japan \\ ${ }^{2}$ Crystalline Environment Engineering Group, Geological Isolation Research and Development Directorate, Japan Atomic Energy Agency, \\ 1-64 Yamanouchi, Akeyo-cho, Mizunami 509-6132, Japan
}

(Received February 16, 2012; Revised June 21, 2012; Accepted June 26, 2012; Online published March 6, 2013)

\begin{abstract}
We used a gPhone (serial number 90), the newest spring-type gravimeter manufactured by Micro-g LaCoste Inc., to acquire high-quality, continuous gravity records, both below- and aboveground. At a depth of $100 \mathrm{~m}$, when the gPhone was situated under an uncon ned aquifer, the standard deviations of the residual gravity based on rst- and second-order curve ttings are 4.2 and $2.7 \mu \mathrm{Gal}$, respectively. Some gravity decreases caused by rainfall were clearly observed, and unknown gravity variations may also have occurred. Alternatively, when the gPhone was placed aboveground on the ank of a high mountain, the standard deviation of the residual gravity was $1.7 \mu \mathrm{Gal}$ for both the rst- and second-order curve ttings. The rainfall amount and snow depth can explain most of the residual gravity. On the basis of these results, we propose to detect and correct hydrological gravity responses using multiple gravimeters to study gravity signals from deep within the earth.
\end{abstract}

Key words: Gravity, gravity monitoring, gravimeter, groundwater, inland water, hydrology, rainfall, snow depth.

\section{Introduction}

The study of hydrological effects on continuous gravity observations has been shifting from the use of empirical to physical models in recent years. Kazama and Okubo (2009) and Naujoks et al. (2010) calculated the water distribution around a gravity observation point such that hydrological simulations based on both hydrogeological observations and subsurface-structure assumptions and surveys were needed. It was natural that these hydrological models did not include unknown inland water ows.

Tanaka et al. (2006) determined the groundwater-togravity response factors of both uncon ned and con ned aquifers at an aboveground measurement site. The gravity variations caused by rainfall were consequently eliminated using an uncon ned response factor (see Section 5). It was merely due to accidental good luck that a groundwater-level observation well represented inland water variation in the vicinity of a gravity observation point. Moreover, Tanaka et al. (2006) concluded that a gravimeter is the best device for monitoring the total mass of groundwater change. In recent years, the tilt meter is also used for validation of the groundwater level change (Matsuki et al., 2008; Queitsch et al., in press).

Here, we apply the use of an effective method called the

*Now at MAEDA CORPORATION Kansai branch, 2-5-30 Kyutaromachi, Chuo-ku, Osaka 541-8529, Japan.

Copyright (C) The Society of Geomagnetism and Earth, Planetary and Space Sciences (SGEPSS); The Seismological Society of Japan; The Volcanological Society of Japan; The Geodetic Society of Japan; The Japanese Society for Planetary Sciences; TERRAPUB.

doi:10.5047/eps.2012.06.012 "gravimeter array method" (Tanaka, 2010a) to remove the gravity change caused by inland water uctuations by cancellations using two continuous gravimeters with a free water plane between them. Although it is a rare environment in which a gravimeter can be installed under a free water plane, such an installation would be possible if the performance of borehole gravimeters were to improve in the future. In this case, gravimeter users could correct changes in gravity caused by inland water uctuations without hydrological model construction, if borehole gravimeters are adopted in a nationwide, high-density observation network. It is reasonable that a spring-type gravimeter could be installed underground or in a borehole due to the reasons discussed below. The gPhone gravimeter, manufactured by Micro-g LaCoste, Inc. (Lafayette, Colorado, USA), is the one of the most recent gravimeters that has been tuned to make continuous observations. We should mention that the ZLS Corp. (Austin, Texas, USA) has also developed an attractive gravimeter. The establishment of a gravimeter array method is the rst step in clarifying whether a gPhone can detect gravity changes caused by inland water uctuations. Since the gPhone was introduced at the end of 2009, we have been devising effective installation and data analysis methods through trial and error as well as through the use of some observation points. In addition, apparent gravity changes accompanied by anomalous sensor temperature changes and tilt instability in nonrecommended observation environments have been found (see Section 3). Riccardi et al. (2011) also reported that a gPhone has a lower long-term stability and a higher noise level than a superconducting gravimeter. However, the 


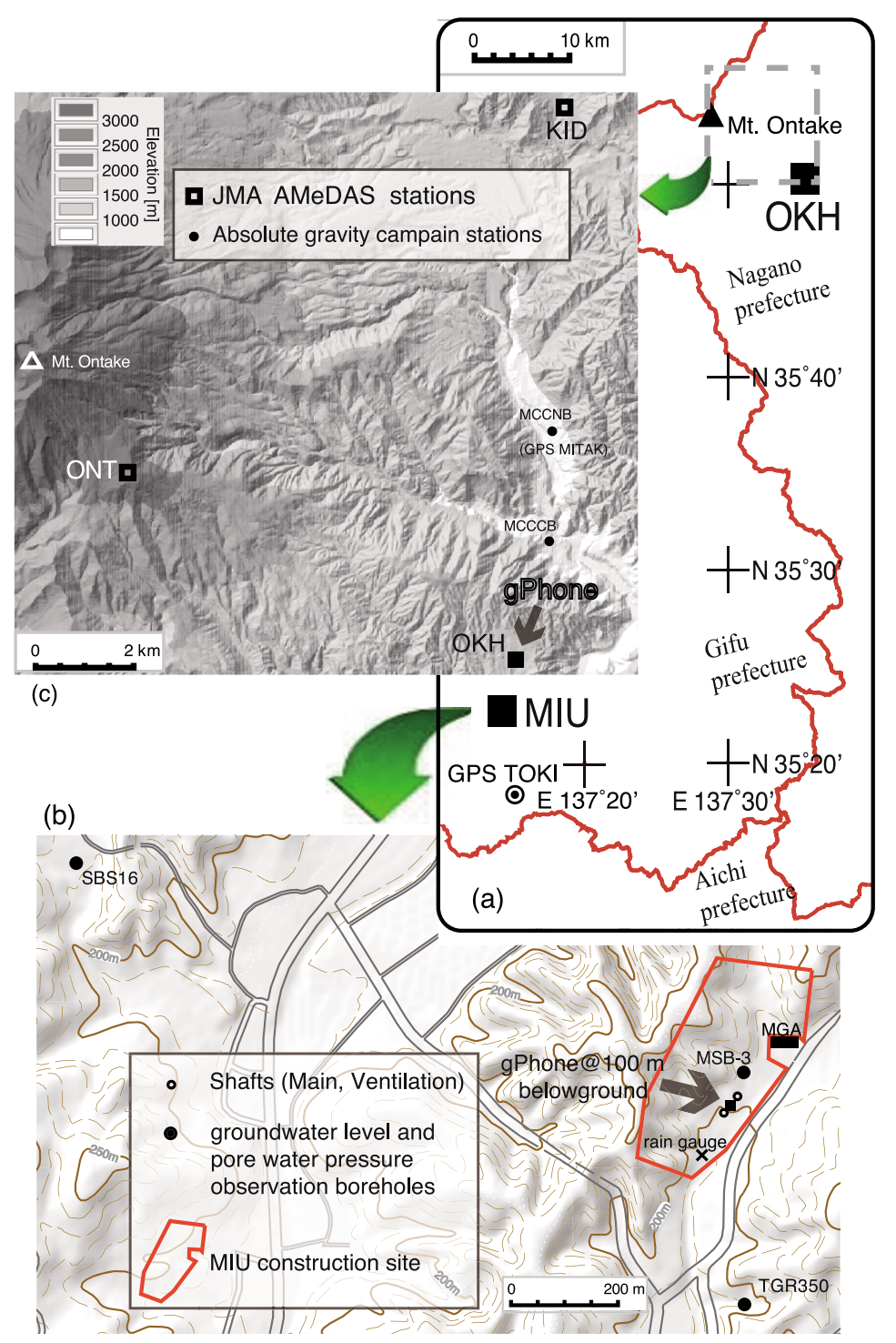

Fig. 1. Map showing the location of the Mizunami Underground Research Laboratory (MIU) and the Ontake Kougen Hotel (OKH), where continuous gravity observations were performed. (a) Regional map of Gifu, Nagao, and Aichi prefectures, Central Japan. The GPS station TOKI (ID:020994 of GEONET of the Geospatial Information Authority of Japan) is also shown. (b) Topographic map with roads around the MIU construction site. The closed square denotes the refuge area of the 100-m sub-stage (at a depth of $100 \mathrm{~m}$ below the surface) where a gPhone-90 was set up during the summer of 2010. A sub-stage is a horizontal tunnel between the Main shaft (northeast open circle) and the Ventilation shaft (southwest open circle) at every $100 \mathrm{~m}$ in depth. The label MGA denotes the Mizunami Geoscience Academy building. (c) Topographic relief map of the eastern flank of the Mt. Ontake Volcano. The gPhone-90 was set up in the elevator engine room of the OKH (solid square) from the winter of 2010 to the spring of 2011. The two open squares show the Automated Meteorological Data Acquisition System (AMeDAS) stations (KID, Kaida-kogen; ONT, Ontakesan) of the Japan Meteorological Agency (JMA).

portability and ease of operation and maintenance of the gPhone justifies its use for the present time. In this report, we investigate the relationship between local inland water and gravity measurements at two observation sites at the Mizunami Underground Research Laboratory (MIU; installation period: July-November 2010) and the Ontake Kougen Hotel (OKH; installation period: November 2010April 2011) (Fig. 1). We then discuss a more effective gravity-monitoring method that does not take hydrological modeling into account. However, we use records of only approximately two months at each site to avoid including man-made disturbances and earthquake motions in the analysis.

\section{Observations}

While collecting the following observations, we attached standard accessory pads to the leg of a gPhone sensor (Meter box). Although this caused decreases in sensitivity for a short period (Micro-g LaCoste, Inc., 2008), this attachment was added to decrease artificial vibration disturbances caused by a drainage system near the meter at the MIU and by earthquakes that were frequently sensed directly under the OKH (Fig. 1). The level-checking procedure for the Meter box might not have been optimized because it was based on an old manual (Micro-g LaCoste, Inc., 2008, 2010). However, the influence of the incomplete level check was mostly reduced by the data analysis device (Section 3 ). The timing module was equipped with a gPhone with a GPS- 
synchronizing rubidium clock and was nonfunctional because the antenna cable was too short. Therefore, the clock of the PC used to control and acquire data was corrected with the Network Time Protocol (NTP). Vibrations from the electronics box - mainly from the uninterruptible power supply (UPS)—were suppressed with a resilient isolator. The sensor drift rates were -6 to $-5 \mu \mathrm{Gal} /$ day at the MIU and -4 to $-3 \mu \mathrm{Gal} /$ day at the OKH. Both of these rates decreased over time. Fortunately, these rates are considerably smaller than those of the gPhone-054 drift (Riccardi et al., 2011).

The introduction of the gPhone-90 was intended for installation at the MIU. However, at the time, the background noise level at the MIU was high due to construction, research, and educational activities. Therefore, observations without either arti cial disturbances or human activities, such as the conditions that were available around Mt. Ontake, were also necessary to evaluate the intrinsic performance of the gPhone. In addition, since 2004, we have been conducting repeated measurements using a FG5 absolute gravimeter on the eastern ank of Mt. Ontake (two solid circles in Fig. 1(c)). When the relationship between gravity and precipitation is revealed by continuous gPhone observations near the absolute gravity observation sites, an assessment of precipitation to absolute gravity records may be possible.

\subsection{Belowground observations at the MIU (100-m depth)}

We installed a gPhone-90 in the refuge area of the 100m-deep sub-stage (sub-stage is a horizontal tunnel between the Main and Ventilation shafts) in July 2010. Because the oor was made of uneven concrete, we laid a stainless steel plate of 1.2-mm thickness under the Meter box. The Longlevel tilt change of approximately 1000 analog-digital units (AD units) occurred, which far exceeded the standard 500 AD units (Micro-g LaCoste, 2008). Here, the Long direction is perpendicular to a sub-stage tunnel, approximately NW-SE. The number of AD units multiplied by a userde ned coef cient became the radian-unit tilt. Here, the user-de ned coef cient means a calibration factor, which was uniquely determined by collecting a certain number of calibration data (the relationship between gravity and tilt) with a least-squares method (Micro-g LaCoste, 2008). As the tilt change steadily increased, the in uence on gravity records was also monotonous.

A piece of styrofoam was used to cover the Meter box to suppress the in uences of both ambient temperature change and high humidity. The temperature and humidity in the analysis period still changed between certain ranges: $23-27^{\circ} \mathrm{C}$ and $60-80 \mathrm{RH} \%$, respectively. The temperature change slightly correlated with the level change.

Data were recorded every 1 second. We used the gMonitor software (Micro-g LaCoste, 2009), which stored a binary le and two text les ( $1 \mathrm{sec}$ sampling and $5 \mathrm{~min}$ sampling). The 5-min interval data is used for long-term realtime display and has a delay of approximately 12 minutes as a result of down-sampling ltering, so that it was inappropriate for data analysis.

We used a rain gauge at the MIU construction site (Fig. 1(b)) to determine 1-hour integrated rainfall data, which was originally a 10 -minute sampling rate with a 0.5 $\mathrm{mm}$ resolution, for the comparison with gravity.

\subsection{Aboveground observations at Mt. Ontake}

We installed the gPhone-90 in the elevator room of the OKH on the southeastern ank of Mt. Ontake (Fig. 1(c)). The OKH was closed for the winter season during our observation period. The oor surface was composed of slightly uneven concrete, so we installed a square $(30 \times 30 \times$ $2 \mathrm{~cm}$ ) hard tile on a thin layer of gypsum and set the Meter box on it. As a result, the tilting of the Meter box in both directions (Cross and Long) was less than several hundred AD units. Here again, we used a styrofoam casing and adopted a 1-second sampling rate.

We made use of the Automated Meteorological Data Acquisition System (AMeDAS) data of the Japan Meteorological Agency (the Ontakesan (ONT) site provided rainfall data and the Kaida-kogen (KID) site provided snow depth data, shown as two open squares in Fig. 1(c)). Although the ONT is closer to the OKH than the KID, snow depth observations were not available from ONT.

\section{Data Analysis}

The 1-second data obtained using the gPhone were downsampled to 1-hour data through a least-squares ltering in Tsoft (Van Camp and Vauterin, 2005). Afterward, the tidal analysis program BAYTAP-G (Tamura et al., 1991) was used to decompose the gravity data into four components, namely tidal, trend, irregular, and response for auxiliary data. The input gravity for BAYTAP-G was derived by subtracting both Polar Motion Correction based on IERS Bulletin (http://maia.usno.navy.mil/) and Level Correction calculated from observed level changes with user-de ned parameters (Subsection 2.1) from raw gravity. The Polar Motion Correction and Level Correction are the name of row the gMonitor software outputs. We used ambient pressure, sensor temperature, and level correction (in duplicate) as auxiliary data. The reason for the use of duplicate data was that the trend components derived by BAYTAP$G$ were correlated with level corrections in a preliminary analysis, indicating probable incompleteness of the userdetermined coef cients in the level check procedure mentioned in Section 2. Additionally, the reason for using the sensor temperatures as auxiliary data was that the sensor temperatures are usually self-regulated to an order of $10^{-4}$ degrees, but a step-like change of an order of $10^{-3}$ degrees that occurred less than once a month produced an approximately $2.6 \mu \mathrm{Gal}$ per $10^{-3 \circ} \mathrm{C}$ gravity change (Tanaka, $2010 \mathrm{~b}$ ). This result seemed to be particular to the gPhone90 (Derek von Westrum of Micro-g LaCoste, Inc., personal communication).

Figure 2 shows that the residual gravity of the two sites was derived from the trend components of BAYTAP-G through subtractions of linear and quadratic equations obtained through least-squares tting. Note that the negative direction of the residual gravity indicates an increase in gravity. Although the actual data analysis periods were longer than those presented here, we focused our examination on periods when arti cial and seismic disturbances were relatively low to detect gravity changes caused by precipitation. 

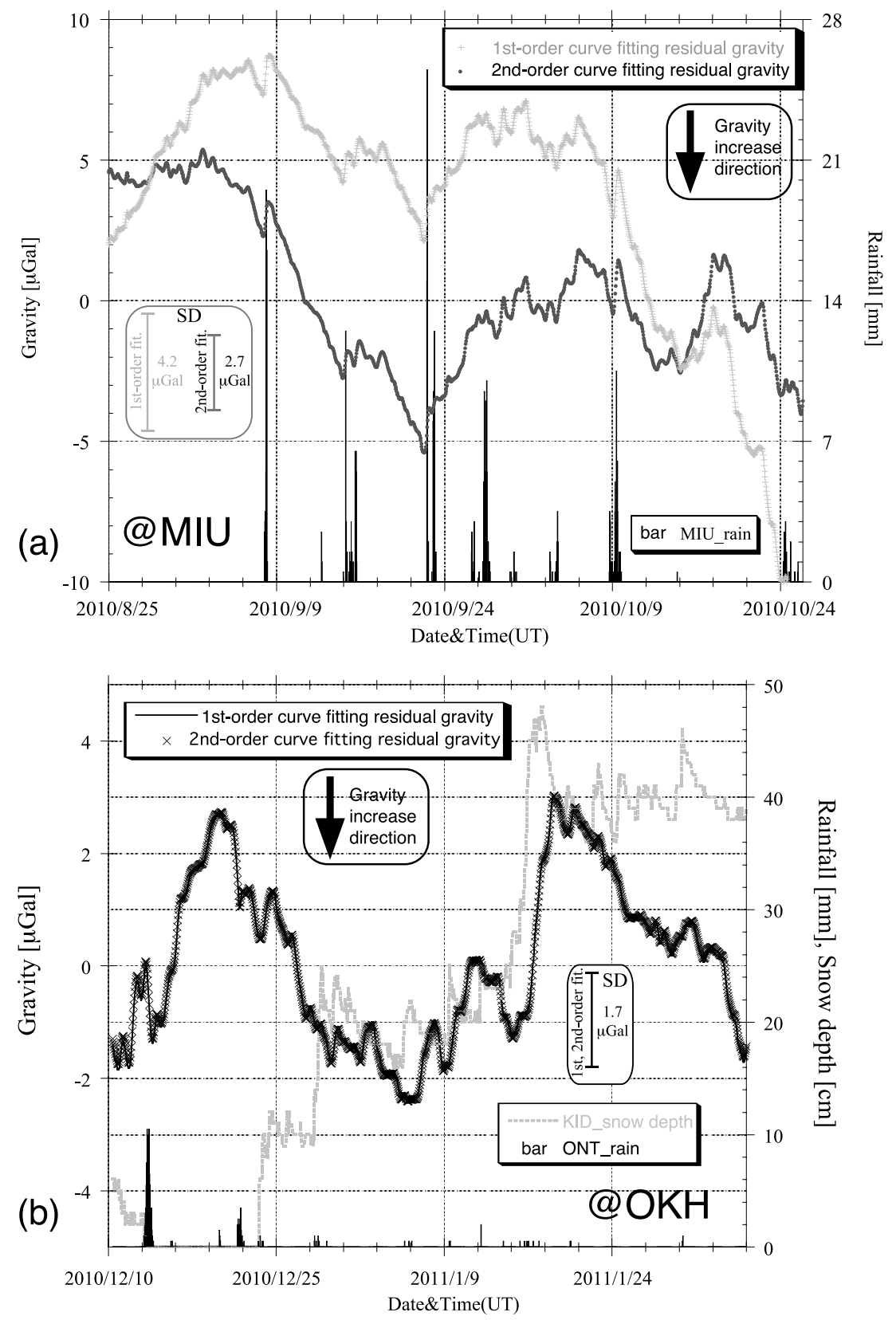

Fig. 2. Comparison of residual gravity (first- and second-order curve fittings) with precipitation. The residual gravity is derived by subtracting a regression curve from the statistically noise-rejected component (or trend component) of the BAYTAP-G (Tamura et al., 1991). The SD is also shown. Note that the negative direction of the residual gravity indicates an increase in gravity. (a) At a depth of $100 \mathrm{~m}$ belowground at the MIU, rainfall data are available from the gPhone at an approximately 100-m horizontal distance (Fig. 1(b)). (b) At the surface of the southeastern flank of Mt. Ontake, no significant difference is seen between the first- and second-order curves. Rainfall data are available from the gPhone at a horizontal distance of approximately $9 \mathrm{~km}$ (Fig. 1(c), ONT), and snow depth data are available from the gPhone at a horizontal distance of approximately $12 \mathrm{~km}$ (Fig. 1(c), KID).

\section{Curve-Fitting Evaluation and Comparison with Precipitation Data}

\subsection{MIU}

As shown in Fig. 2(a), the large difference between the linear equation fitting (SD $4.2 \mu \mathrm{Gal}$ ) and the quadratic equation fitting (SD $2.7 \mu \mathrm{Gal}$ ) may indicate the existence of nonlinear drift (Riccardi et al., 2011). The drift rate from August to the beginning of September may not have been stable because a planned blackout occurred on $\mathrm{Au}$ gust 7. However, the residual gravity resulting from the linear equation fitting might have included real, but unknown, gravity variations on a timescale on the order of months.
Unfortunately, our FG5 absolute gravimeter was not in operation during that period due to problems associated with the laser.

Some gravity responses caused by rainfall were clearly detected as gravity decreases, particularly the responses that occurred on September 8, September 22, and October 9, that were over $1 \mu \mathrm{Gal}$ in amplitude. Gravity responses on the order of sub-microGal were also observed.

\subsection{OKH}

As shown in Fig. 2(b), the difference between the twoways residuals is quite small with the same $\mathrm{SD}(1.7 \mu \mathrm{Gal})$. In other words, the drift rate is extremely linear. A paral- 
lel observation with a FG5 was not initially scheduled. A correlation between the residual gravity and the amounts of rainfall and snow depth is clear, despite the considerable distance between the OKH and the ONT/KID stations (Fig. 1(c)). Therefore, we can interpret Fig. 2(b) as follows:

(1) The gravity increased in December 13 in response to a mass increase below the height of the OKH caused by both rainfall and snowmelt.

(2) Similarly, the gravity increased in December 21 due to rainfall.

(3) As the gravity increased between December 23 and December 28 in response to an increase in mass accompanied by an increase in snow depth below the height of the $\mathrm{OKH}$, the gravity decrease between December 14 and December 21 re ected the mass increase caused by snowfall above the height of $\mathrm{OKH} / \mathrm{KID}$.

(4) After December 29, as the both wavelength gravity and snow-depth shorter than a few days were almost equal (not exactly in phase), the gravity decreased due to snowfall above the height of OKH.

(5) The snow-depth increase of $20 \mathrm{~cm}$ from December 15 to December 18 corresponded to a gravity decrease of $-4.3 \mu \mathrm{Gal}$ from December 16 to December 19, such that an estimated snow density of $500 \mathrm{~kg} / \mathrm{m}^{3}$ was reasonable (Public Works Research Institute, 2009) with the assumption of an in nite slab.

(6) After January 22, a gravity increase corresponded to the mass increase below the height of the OKH that was caused by snow melting below the height of the KID.

\section{Comparison with the Study by Tanaka et al. (2006)}

5.1 Differences from the study by Tanaka et al. (2006)

Tanaka et al. (2006) indicated that the groundwater level (strictly speaking, the pressure head change) of a con ned aquifer in a granite rock basement dominates in gravity variations at the measuring room of the Mizunami Geoscience Academy (MGA) (Fig. 1(b)). The primary cause of the conned groundwater level change is the occurrence of earthquakes. Probe-7 of the MSB-3 borehole that Tanaka et al. (2006) used had been suffering from remarkable arti cial disturbances due to construction work at the MIU since the spring of 2005. Therefore, we used the TGR350 borehole (350-m depth, with casing above the granite basement) (Fig. 1(b)), where the disturbance level was less than at probe-7 of the MSB-3. The TGR350 and MSB-3 boreholes had very similar responses to earthquakes. The long-term decreasing trend of the TGR350 (Fig. 3) was caused by a hydrological test (Tono Geoscience Center, 2011). Tanaka et al. (2006) had studied the gravity and pore pressure data obtained during the effect of two earthquakes (2003 Tokachi-Oki (MJMA 8.0) and 2004 Off the Kii peninsula (MJMA 7.4)) had been included. However, one such response was negligible during the period of this study.

The uncon ned groundwater level in the subsurface Tertiary deposit (Mizunami Group) re ected rainfall, and the contribution to the gravity change was one- fth as com- pared with the con ned groundwater (Tanaka et al., 2006). Instead of the pore pressure of probe-1 of the MSB-3, we used the groundwater level in the SBS16 borehole (a 16-mdeep well in the Akeyo formation of the Mizunami Group) (Fig. 1(b)) in this study where no arti cial disturbance effects were seen.

To evaluate the contribution of the height change of the gravimeter, we utilized a simple method described by Tanaka et al. (2006). One difference between our study and that of Tanaka et al. (2006) was that the analysis of the daily coordinates of the GEONET (GPS Earth Observation Network System by the Geospatial Information Authority of Japan) changed from analysis strategy 3 to 4 (Munekane, 2010). To brie y outline the method, the smoothed ellipsoidal height change of the TOKI station (Fig. 1(a)) was interpolated to the hourly data, by a least-squares method, from the daily one (this oversampling is a merely procedure to unify the sampling intervals) and then the effect of the height change was calculated by multiplying by a free-air gradient. However, at a 100-m depth from the surface, it is unknown whether the application of the surface GPS is appropriate or not, and the resultant effect is small. Therefore, we did not combine the effect in our analysis. Namely, in Fig. 4, the predicted gravity did not take into account of the FA effect.

\subsection{Calculation of gravity change}

The groundwater level changes of both the TGR350 and SBS16 boreholes are shown as $W c$ and $W u$ in Fig. 3 (left vertical axis), respectively. $W c$ clearly responded to tides with the above-mentioned decreasing trend. $W u$ acted as typical uncon ned groundwater, responding quickly to rainfall. Tanaka et al. (2006) de ned a "conversion coef cient from pressure head to gravity" and estimated that each contribution to the gravity change was the con ned aquifer, $C_{\text {conf }}=-6.70$ and the uncon ned aquifer, $C_{\text {unco }}=1.26$ $\mu \mathrm{Gal} / \mathrm{m}$, respectively (namely, $\left|C_{\text {unco }}\right|$ is a one fth of $\left|C_{\text {conf }}\right|$ as mentioned above).

The height change effect $(-3.059 \mu \mathrm{Gal} / \mathrm{cm}$ that was used as a free-air gradient (Tanaka et al., 2006) of the gravimeter is shown in Fig. 3 (the right vertical axis) as an FA effect. However, the height change was smoothed and interpolated from the daily solution to hourly data. Uplift was in the positive direction of the vertical axis. The FA effect was less than approximately $1 \mu \mathrm{Gal}$, so we ignore it in the following discussions.

The sign of $C_{\text {unco }}$ reversed compared with Tanaka et al. (2006) because the gPhone at the 100-m sub-stage was under the uncon ned aquifer. Thus, the total gravity effect of $W c$ and $W u, \Delta g p$, is expressed as follows:

$$
\Delta g p=-C_{\text {unco }} W u+C_{\text {conf }} W / c
$$

Here, $W / c$ (the broken line overlaid on $W c$ in Fig. 3) indicates the smoothed $W c$, which represents the suppression of diurnal/semidiurnal tide uctuations by a weighted leastsquares method (Chambers et al., 1983). A data point for $W u$ is missing for September 23 due to a temporary fault of data acquisition. Some step-shaped gravity decreases corresponded to an abrupt increase of $W u$ when rainfall occurred. Additionally, these amplitudes are somewhat small and almost the same despite daily (not hourly) Cunco and 

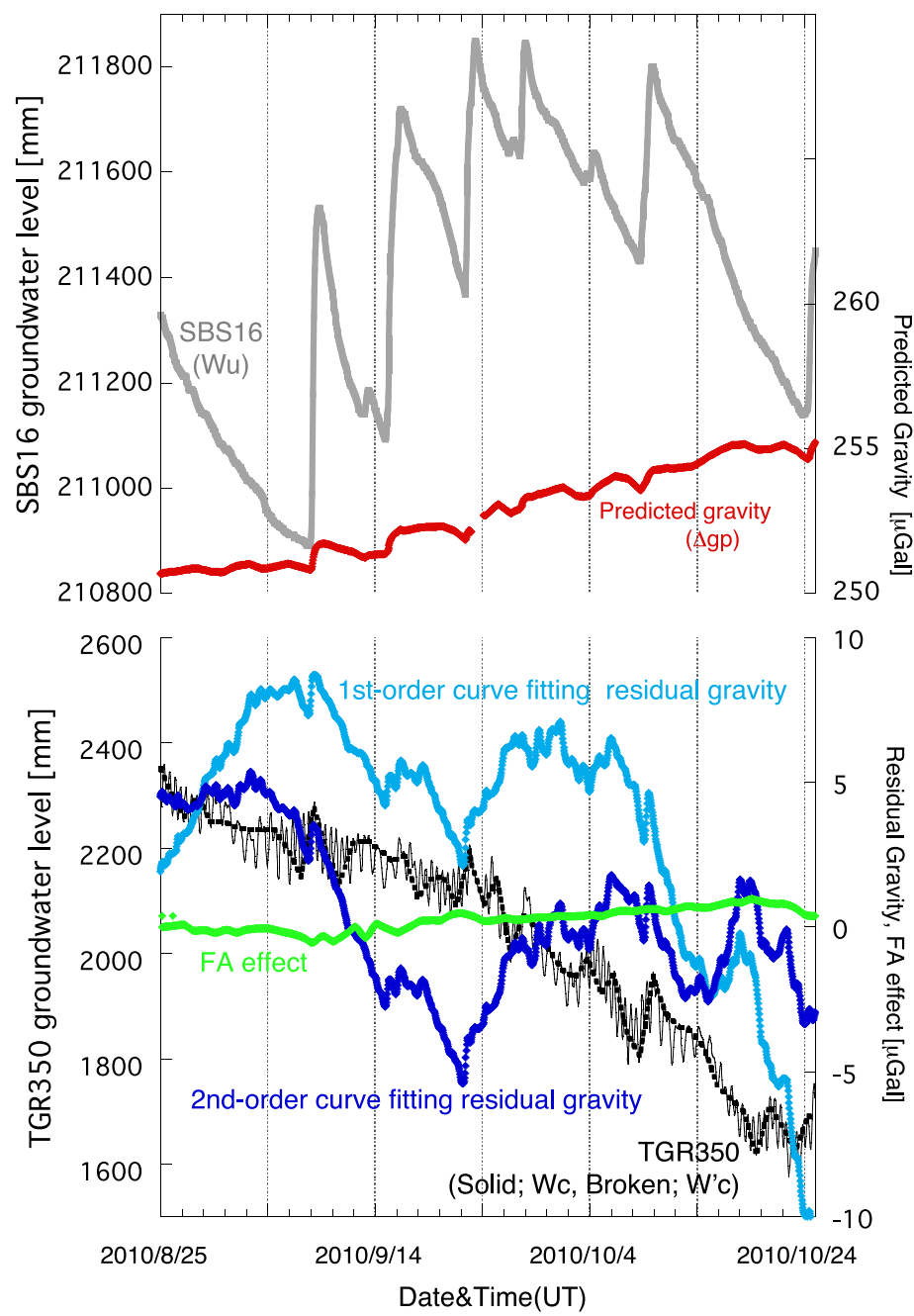

Fig. 3. Groundwater levels ( $W u$, unconfined SBS16; $W c, W / c$, confined TGR350), the free-air (FA) gradient effect, residual gravity (first- and second-order curve fittings), and predicted gravity levels calculated from the two groundwater levels are shown. $W / c$ (bold dashed line) represents the $W c$ curve smoothed (thin solid line) using a weighted least-squares method (Chambers et al., 1983) to reduce diurnal-semidiurnal tidal variations.

SBS16 (not MSB-3) measurements. The decreasing trend of $\Delta g p$ reflects the decreasing trend of $W c$. The effect of rainfall is dominant over $\Delta g p$ except in the hydrological test. Therefore, for the two forms of residual gravity, neither the fluctuations in the peak-to-peak amplitude of 5 $\mu \mathrm{Gal}$ with a wavelength of 10-15 days, nor the peak-topeak amplitude of less than $1 \mu \mathrm{Gal}$ with a wavelength of 1 day, can be explained by the framework of Tanaka et al. (2006). With only one gPhone gravimeter, it is impossible to determine the cause of the fluctuations, whether from a non-linear spring response (Riccardi et al., 2011), or an origin with an unknown gravity change.

\section{Discussion and Conclusions}

In this study, we have demonstrated that we can successfully detect gravity variations of hydrological origin of approximately $1 \mu \mathrm{Gal}$ using a gPhone, as already many observations using superconducting gravimeters have been reported (Kroner et al., 2004; Kazama et al., 2012 and references there-in). Belowground at the MIU, gravity decreases that reflected mass increases above the gravimeter due to rainfall were observed. The estimated gravity response of rainfall with the conversion coefficients prepared by Tanaka et al. (2006) was in good agreement to the observed gravity variation, even though the observation environments differed from those of Tanaka et al. (2006). These results validate the approach of Tanaka et al. (2006); namely, a correlation between absolute gravity change and unconfined groundwater level change was successfully established. On Mt. Ontake, aboveground observations indicate that the relationship between gravity change and rainfall-/snow-depth is so strong that gravity effect changes are easily interpretable through sign variations in response to inland water mass changes based on the relative height of the gravimeter. If a rain gauge and a snow-depth meter are installed in the vicinity of a gravimeter site, the correlation between gravity and inland water becomes clearer; therefore, the rain/snow-depth and gravity simultaneous observation may be effective for monitoring calm magma intrusion activity (Nakamichi et al., 2009).

Some problems arise concerning gravity monitoring by gPhone: (1) an apparent gravity change due to anomalous sensor temperature changes was detected as described in Section 3 (it was not shown in this paper, but a step change of approximately $10^{-3}$ degrees occurred between Aug. 29 and Sep. 3); and (2) inappropriate tilt correction parameters 


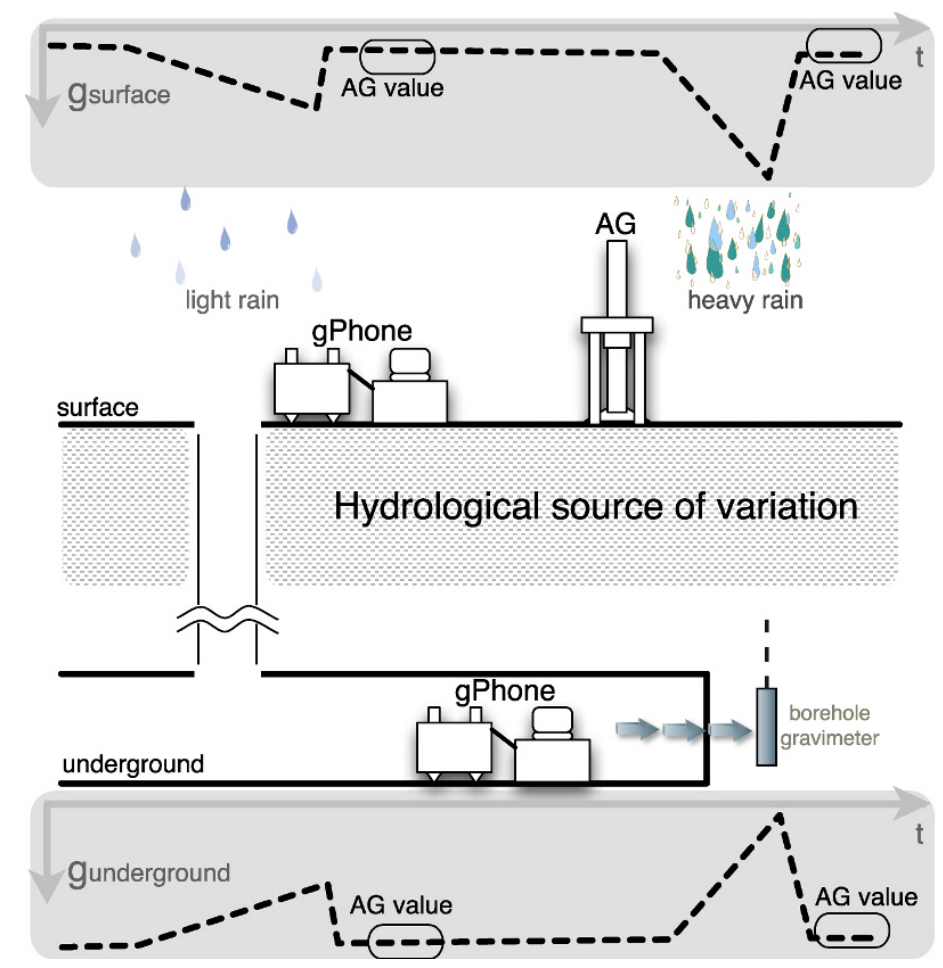

Fig. 4. Illustration of the ideal gravity monitoring system (gravimeter array method) for reducing hydrological gravity disturbances. This article only includes underground and surface gPhone observations. As a result of this study, we suggest that simultaneous operation of both types of gPhone measurements (along with repeated absolute measurements) is the next step for correcting groundwater disturbances. In the future, the underground gPhone could be replaced by a borehole gravimeter to eliminate the need for a large-scale underground facility.

and large tilt over/under $+/-500 \mathrm{AD}$ units, such as in the MIU, may produce improper gravity signals, although these can mostly be overcome using the analytical procedure described in Section 3. With regard to (1), the observations on Mt. Ontake were carried out just after those made at the MIU, so it is unlikely that the sensor of the gPhone-90 malfunctioned.

Based upon the abovementioned information, we can develop the following strategy to study gravity signals from the deep part of the crust/Earth by constructing a gravimeter array method around the MIU in the near future (Fig. 4):

(1) Simultaneous observations can be conducted both above- and belowground using two gPhone gravimeters.

(2) The gravity effect of rainfall can be nearly compensated each other by the sum of two gravity data points, and the signal from the deep part of the subsurface area can be stacked.

(3) The absolute gravity can be measured a few times per month to evaluate the sensor drift of two gPhone gravimeters.

We can avoid the disturbance of rainfall, and obtain highquality absolute values, if we collect measurements during stable weather conditions. Additionally, unnecessary use of the absolute gravimeter should be reduced to save wear and tear on its expendable parts. In the near future, instead of using a gPhone underground, an equivalent (and inexpensive) borehole gravimeter should be developed and installed. If such a borehole gravimeter were incorporated into a device such as a multi-component borehole instrument (Ishii et al.,
2002), the cost of each observation item would decrease. Furthermore, if the borehole device housing the gravimeter were adopted as part of a nationwide observation infrastructure, such as Hi-net (Obara et al., 2005), many observation environments would become available without requiring the construction of local hydrological models, thus enabling the correction of the inland-water gravity effect. Such a gravity monitoring system would contribute not only to geophysical applications, but also to monitoring at geothermal power stations and geological disposal sites.

Acknowledgments. For observations at the MIU, the authors obtained permission and cooperation from the Tono Geoscience Center, the Japan Atomic Energy Agency and the Mizunami City Office. For observations on Mt. Ontake, the authors obtained permission and cooperation from the Ontake Kougen Hotel (now the Ontake Golf \& Resort Hotel). We also acknowledge Drs. C. K. Shum and G. Jentzsch for their help in improving the manuscript. T. Tanaka gives thanks to Dr. K. Nawa of the National Institute of Advanced Industrial Science and Technology and Dr. Y. Imanishi of the University of Tokyo for helpful advice regarding the operation and data handling of the gPhone. This work was supported by a promotion grant for the establishment of the underground research facility of the Agency for Natural Resources and Energy, Minister of Economy, Trade and Industry. T. Tanaka and Y. Asai are supported by the special cooperative research grant (2010-B-01) of the Earthquake Research Institute of the University of Tokyo. The authors used AMeDAS data of the Japan Meteorological Agency and GEONET data of the Geospatial Information Authority of Japan from those Agencies' official web sites.

\section{References}

Chambers, J. M., W. S. Cleveland, B. Kleiner, and P. A. Tukey, Graphical Methods for Data Analysis, 395 pp., Duxbury Press, Boston, 1983. 
Ishii, H., T. Yamauchi, S. Matsumoto, Y. Hirata, and S. Nakao, Development of multi-component borehole instrument for earthquake prediction study, some observed example of precursory and co-seismic phenomena relating to earthquake swarms and application of the instrument for rock mechanics, Seismogenic Process Monitoring, 365-377, 2002.

Kazama, T. and S. Okubo, Hydrological modeling of groundwater disturbances to observed gravity: Theory and application to Asama Volcano, Central Japan, J. Geophys. Res., 114, B08402, 2009.

Kazama, T., Y. Tamura, K. Asari, S. Manabe, and S. Okubo, Gravity changes associated with variations in local land-water distributions: Observations and hydrological modeling at Isawa Fan, northern Japan, Earth Planets Space, 64, 309-331, 2012.

Kroner, C., T. Jahr, and G. Jentzsch, Results of 44 months of observations with a superconducting gravimeter at Moxa/Germany, J. Geodyn., 38(35), 263-280, 2004.

Matsuki, K., K. Nakatani, T. Arai, K. Ohmura, R. Takeuchi, Y. Arai, and S. Takeuchi, A quadratic element method for evaluating groundwater ow by the inversion of surface tilt with application to the Tono Area, Japan, J. Hydrol., 360, 217-229, 2008.

Micro-g LaCoste, Inc., gPhone/P.E.T Hardware Manual V1, 2008.

Micro-g LaCoste, Inc., gMonitor User's Manual, 2009.

Micro-g LaCoste, Inc., gPhone Hardware Manual Version 2.0, 2010.

Munekane, H., On Improving Precision of GPS-derived Height Time Series at GEONET Stations, Bull. GSI, 58, 39-46, 2010 (available at http://www.gsi.go.jp/ENGLISH/page_e30092.html).

Nakamichi, H., H. Kumagai, M. Nakano, M. Okubo, F. Kimata, Y. Ito, and K. Obara, Source mechanism of a very-long-period event at Mt Ontake, central Japan: Response of a hydrothermal system to magma intrusion beneath the summit, J. Volcanol. Geotherm. Res., 187, 167-177, 2009.

Naujoks, M., C. Kroner, A. Weise, T. Jahr, P. Krause, and S. Eisner, Evaluating local hydrological modeling by temporal gravity observations and a gravimetric three-dimensional model, Geophys. J. Int., 182, 233-249, 2010.

Obara, K., K. Kasahara, S. Hori, and Y. Okada, A densely distributed highsensitivity seismograph network in Japan: Hi-net by National Research Institute for Earth Science and Disaster Prevention, Rev. Sci. Instrum., 76, 021301, 2005
Public Works Research Institute, Measuring accumulated snowfallResearch on snow-melt runoff characteristics in snowy cold regions-, PWRI Web Magazine, 10, 2009 (available at http://www.pwri.go.jp/ eng/webmag/wm010/index.html).

Queitsch, M., G. Jentzsch, A. Weise, H. Ishii, and Y. Asai, Pumping induced pore pressure changes in tilt measurements near a fault zone in Mizunami (Japan), Proceedings of the IAG Special Session at the IUGG Conference in Melbourne, 2011 (in press).

Riccardi, U., S. Rosat, and J. Hinderer, Comparison of the Micro-g LaCoste gPhone-054 spring gravimeter and the GWR-C026 superconducting gravimeter in Strasbourg (France) using a 300-day time series, Metrologia, 48, 28-39, 2011.

Tamura, Y., T. Sato, M. Ooe, and M. Ishiguro, A procedure for tidal analysis with a Bayesian information criterion, Geophys. J. Int., 104, 507-516, 1991

Tanaka, T., Performance evaluation of "gPhone" and its application plans, Chikyu Monthly, 367, 258-263, 2010a (in Japanese).

Tanaka, T., Introduction/adjustment of gPhone and its present condition of the data, Rep. Tono Res. Inst. Earthq. Sci., 25, 75-81, 2010b (in Japanese).

Tanaka, T., W. Salden, A. J. Martin, H. Saegusa, Y. Asai, Y. Fujita, and H. Aoki, Variations of absolute gravity accompanying earthquake-induced changes in subsurface pore water pressure at the Mizunami Underground Research Institute construction site, central Japan, Geochem. Geophys. Geosyst., 7, Q03017, 2006.

Tono Geoscience Center, Mizunami Underground Research Laboratory project report of 2010 scal year, 2011 (in Japanese) (available at http://www.jaea.go.jp/04/tono/jigyou/110421/h22.pdf).

Van Camp, M. and P. Vauterin, Tsoft: Graphical and interactive software for the analysis of time series and Earth tides, Comput. Geosci., 31(5), 631-640, 2005 .

T. Tanaka (e-mail: tanaka@tries.jp), R. Miyajima, H. Asai, Y. Horiuchi, K. Kumada, Y. Asai, and H. Ishii 